\title{
Testing the relative importance of local resources and landscape connectivity on Bombus impatiens (Hymenoptera, Apidae) colonies
}

\author{
John D. HerRmanN ${ }^{1,2,3}$, Nick M. HADDAD ${ }^{4}$, Douglas J. LeVEY ${ }^{5}$ \\ ${ }^{1}$ Department of Biology, University of Washington, Seattle, WA 98195-1800, USA \\ ${ }^{2}$ Department of Plant Biology, Michigan State University, East Lansing, MI 48824, USA \\ ${ }^{3}$ Department of Landscape Ecology, University of Kiel, Olshausenstr, 75, 24118, Kiel, Germany \\ ${ }^{4}$ Department of Applied Ecology, North Carolina State University, Raleigh, NC 27695-7617, USA \\ ${ }^{5}$ Division of Environmental Biology, National Science Foundation, Arlington, VA 22230, USA
}

Received 19 November 2015 - Revised 24 November 2016 - Accepted 18 January 2017

\begin{abstract}
Bee populations are decreasing worldwide. The underlying causes are likely determined by factors at different scales. We tested the relative importance of local resources and landscape connectivity on 64 bumblebee (Bombus impatiens ) colonies in experimentally isolated and connected habitat fragments. We used colony mass, no. of workers, and no. of gynes to estimate colony performance. Landscape connectivity did not significantly affect colony performance, but local floral resources had a significantly positive effect, especially in isolated fragments. These results suggest that bumblebee colonies encountered sufficient floral resources within the local 1.4 ha habitat fragments to support colony growth, making long-distance foraging trips to neighboring fragments unnecessary. From a conservation perspective, we suggest that efforts to improve colony performance should prioritize boosting local floral resources over manipulation of large-scale landscape features.
\end{abstract}

agri-environment scheme / foraging distance / landscape connectivity / habitat fragmentation / floral resources

\section{INTRODUCTION}

Insect pollinators are suffering sharp declines in abundance and richness, worldwide (Potts et al. 2010). These declines have led to a simultaneous decrease of ecosystem services that pollinators provide (Cunningham 2000) and may have triggered a global pollination crisis (Steffan-Dewenter et al. 2005). Reduced pollination is a concern because of its importance for conservation of global biodiversity (Bodin et al. 2006) and human food production (Potts et al. 2010). Conservation strategies are urgently needed to counteract ongoing pollinator declines and sustain pollination services (Committee

Corresponding author: J. Herrmann, eco.herrmann@gmail.com

Handling editor: Yves Le Conte on the Status of Pollinators in North America 2007, Daily 1997, Kremen et al. 2002). A first step is to identify and assess potential causes of population declines.

Habitat loss has been identified as one of the most important drivers of pollinator declines (Potts et al. 2010). Decreasing habitat connectivity, which typically accompanies habitat loss, is also thought to negatively affect pollinator populations, but positive as well as negative effects of connectivity on pollinator populations have been observed (e.g., Schüepp et al. 2011, Steffan-Dewenter \& Tscharntke 1999).

The contrasting conclusions reached by different studies on connectivity effects may have two main causes. First, results might be artifacts of study design, particularly when some designs fail to separate effects of habitat loss from those of habitat connectivity (Hadley \& Betts 2012). This almost inevitable link between habitat loss and 
connectivity continues to generate controversy among landscape ecologists regarding their independent effects and the importance of separating them (Bailey et al. 2010, Doerr et al. 2011, Fahrig 2013, Hodgson et al. 2009, 2011). Second, structural connectivity (i.e., physical contiguity of landscape elements) and functional connectivity (i.e., behavioral responses that vary among species and result in different probabilities of travel between landscape elements) may not be synonymous for some organisms. This distinction becomes important when an organism's movement is not confined to its preferred habitat, which is common (Kuefler et al. 2010, Haddad \& Tewksbury 2005, Tischendorf \& Fahrig 2000).

Structural connectivity can be increased through landscape corridors, strips of habitat that connect otherwise isolated fragments of the same habitat (Hilty et al. 2006). Increased structural connectivity may lead to increased functional connectivity by facilitating movement between otherwise isolated habitat fragments (Haddad et al. 2015). Insect pollinators have been observed to use habitat strips and landscape features (e.g., hedgerows) as corridors (Cranmer et al. 2012), and it has been experimentally demonstrated that corridors increase pollen transfer between habitat fragments that they connect (Townsend \& Levey 2005), leading to increased reproductive success of plants (Cranmer et al. 2012, Tewksbury et al. 2002). However, this observed increase in pollinator movement via corridors does not provide evidence that habitat connectivity also benefits the pollinators (Hogdson et al. 2011). Although it is thought that pollinator fitness will increase with structural connectivity (Hopfenmüller et al. 2014), it remains untested whether increased structural connectivity increases pollinator fitness through functional connectivity (Hadley \& Betts 2012).

In addition to large-scale effects such as connectivity between fragments, population dynamics of many species are determined by processes occurring at smaller scales, for example, in a single fragment (McGarigal and Cushman 2002). Even though many pollinators are regarded as highly mobile foragers that perceive resources at large spatial scales (e.g., bumblebees; Westphal et al. 2006), survival of pollinators may most strongly depend on resource quality at small spatial scales, such as flower density in a habitat fragment (Rundlof et al. 2008). Offspring production of solitary bees nesting in high-quality habitat, for instance, was buffered against negative isolation effects by switching to local floral resources when other resources were too distant (Williams \& Kremen 2007). The importance of local resources, however, might be contingent upon accessibility and amount of additional resources in the surrounding landscape.

Within a large-scale landscape experiment composed of seminatural savanna fragments, we tested the effects of landscape connectivity and local floral resources on bumblebee (Bombus impatiens ) colonies. We established bumblebee colonies in fragments, which were either isolated or connected to neighboring fragments via a corridor. By simultaneously measuring corridor and local resource effects on different parameters of colony growth, we avoided pitfalls associated with visual surveys of pollinators and gained direct estimates of colony performance (Heard et al. 2007). Measuring multiple metrics of colony performance is important, as conservation measures need to be based on both short-term fitness parameters (e.g., colony mass and number of workers) and long-term fitness parameters (e.g., number of virgin queens produced to establish new colonies). We hypothesized that (i) colony performance is higher in connected than in unconnected fragments, (ii) local floral resources increase colony performance, and (iii) colony performance depends more on local floral resources in unconnected than in connected fragments.

\section{MATERIAL AND METHODS}

\subsection{Study sites}

We tested our hypotheses in a large experimental landscape at the Savannah River Site (SRS) in South Carolina, USA (Figure 1a). Eight replicate landscapes (hereafter "blocks") consisting of fragments and corridors of open habitat were created in 1999/2000 (six blocks) and 2007 (two blocks) by clearing mature pine forest. The cleared areas are being actively restored to longleaf pine savanna through implementation of prescribed fires on a 2-3-year rotation, planting of longleaf pine 
a

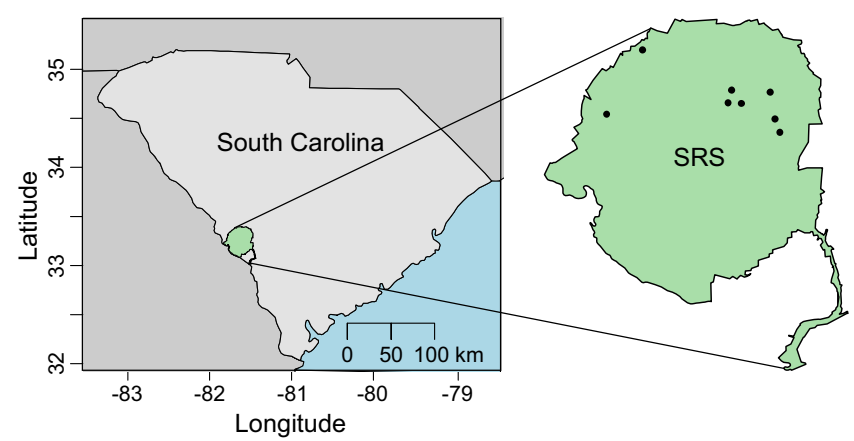

b

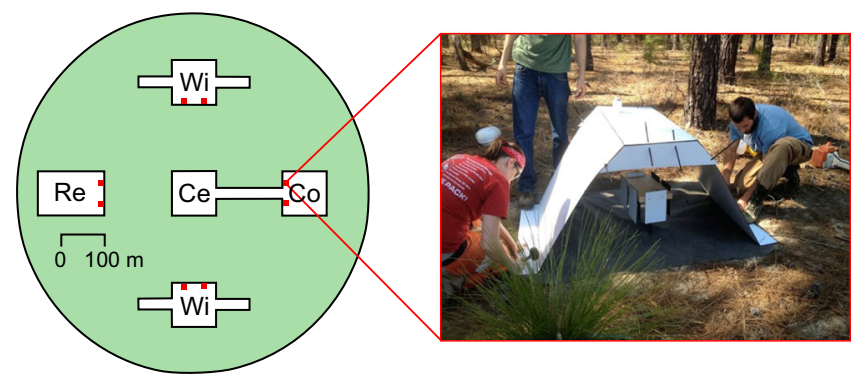

Figure 1. a Locations of the eight experimental blocks (black circles) at the Savannah River Site (SRS) in South Carolina (USA). b One experimental block with one center fragment $(\mathrm{Ce})$ and four peripheral fragments: One peripheral fragment is connected by a $150 \times 25 \mathrm{~m}$ corridor $(\mathrm{Co})$, whereas the rectangular $(R e)$ and winged $(\mathrm{Wi})$ fragments are isolated by mature pine forest. All blocks contain one duplicate unconnected fragment type. Two Bombus impatiens colonies (red box) were established within protective setups in each peripheral fragment

seedlings (Pinus palustris ), and removal of hardwoods. Each block consists of one center fragment $(100 \mathrm{~m} \times 100 \mathrm{~m})$ surrounded by four peripheral fragments, each $150 \mathrm{~m}$ from the center fragment (Figure 1b). One of the peripheral fragments ("connected fragment") in each block is connected to the central fragment by a $25 \mathrm{~m}$ wide and $150 \mathrm{~m}$ long corridor. The other three peripheral fragments are isolated from the central fragment by $150 \mathrm{~m}$ of pine forest and are either "rectangular" (100 m x $137.5 \mathrm{~m})$ or "winged" (100 m x $100 \mathrm{~m}$ with two $25 \mathrm{~m} \times 75 \mathrm{~m}$ m projections on opposite sides). While the increased area of rectangular fragments controls for the increased area provided by the corridor of the connected fragments, the projections of the winged fragments control for the area as well as for the shape of the corridor (for more details, see Tewksbury et al. 2002). Each block contained one duplicate rectangular (four blocks) or winged fragment (four blocks). Each block was surrounded by a forested buffer zone with limited management activities (400 m radius around the block's center point). The experimental landscapes have been used to investigate effects of fragment shape and connectivity on dispersal of various organisms, including plants, butterflies, and birds (Herrmann et al. 2016, Haddad 1999, Tewksbury et al. 2002). For the present study, rectangular and winged fragments were both classified and analyzed as "isolated" because local fragment shape was assumed to be of minor importance for resource availability. Connectivity, on the other hand, has been shown to influence the ability of bees to reach remote food sources (Cranmer et al. 2012).

Naturally occurring pollinator communities within the fragments mainly consisted of butterflies (Lepidoptera), flies (Diptera), and beetles 
(Coleoptera). The activity, density, and species richness of Hymenoptera pollinators was relatively low; only a few solitary bees have been observed nesting within the fragments and commercial honeybee hives are not permitted within the borders of SRS. Blocks were at least $1 \mathrm{~km}$ from the border of SRS, but distances were generally much larger (up to $12 \mathrm{~km}$ ).

\subsection{Study species and experimental setup}

Queenright colonies of the common eastern bumblebee (Bombus impatiens Cresson) were obtained from a commercial breeder (Koppert Biological Systems, Romulus, MI, USA). Each colony resided in a plastic nestbox (approx. 34 $\mathrm{cm} \times 29 \mathrm{~cm} \times 29 \mathrm{~cm}$ ) placed within a cardboard box $(35 \mathrm{~cm} \times 30 \mathrm{~cm} \times 25 \mathrm{~cm})$. Each nestbox consisted of two connected compartments, a lower-level compartment (approx. $2 \mathrm{~cm}$ height) containing the queen, and an upper-level compartment containing the workers, brood, and nest structures. Slits in the wall dividing the two compartments were large enough to allow the queen to interact with individuals in the upper compartment, but too small for her to leave the lower compartment. Two holes in the nestbox allowed bumblebees from the upper compartment to exit or enter the colonies. A one-way flap within each hole allowed bees to only exit or only enter through a given hole. At the beginning of the experiment, each nestbox contained 15-30 workers, one queen, brood, and honey stores.

A pilot study showed that Bombus impatiens colonies were able to successfully forage in our experimental blocks, but that heat and fire ants (Solenopsis invicta) were major threats to colony survival. Thus, all colonies in the current study were protected from the sun by a roof made of corrugated white plastic and protected from fire ants by placement on platforms which were elevated by $30-\mathrm{cm}$ rebar stilts covered with TangleTrap (Contech Enterprises Inc., Victoria, BC, Canada; Figure 1b). Further, the ground under the colonies was covered with landscape fabric (Blue Hawk Basic; Lowe's, Mooresville, NC, USA) to prevent growing plants from creating new pathways for fire ants to reach the colonies.

In mid-April 2013, two colonies were established in each of the peripheral fragments in all blocks, resulting in a total of 64 colonies (eight blocks $\times$ four peripheral fragments/block $\times$ two colonies/ fragment; Figure 1b). The two colonies were placed along the fragment edge closest to the center fragment, $33 \mathrm{~m}$ from the nearest corner and $33 \mathrm{~m}$ from each other. All colonies were oriented such that entrance and exit holes were facing the center of the peripheral fragment. Two colonies died before the end of the study and were excluded from further analyses.

\subsection{Assessment of mass, colony size, and reproductive success}

We used three metrics of colony performance: increase in mass, increase in total number of workers, and increase in number of virgin queens (gynes, hereafter). Each nestbox was removed from its cardboard box and weighed to determine the mass gain of the colony. Thus, colony mass includes colony structures (e.g., wax cells, honey) as well as bumblebees in all developmental stages. To provide baselines, each colony was weighed and the number of bumblebees counted before placement in the field. Once in the field, each colony was weighed after 9, 30, and 51 days. To minimize the number of bumblebees outside their home colony during weighing, the weighing took place between 8:00 and 11:00 h (except on day 0 and 51; see below). The exit but not entrance hole of each colony was closed for at least $2 \mathrm{~h}$ prior to weighing to provide workers enough time to return to the colony. Single bumblebees could still be found outside of the colony during weighing, but their numbers were roughly equal among colonies. After 51 days, the colonies were removed from the field at night (22:00-3:00 h). Any bumblebees on top or below the cardboard box at that time were collected and added to the respective colony.

Colonies were transferred into large plastic bags and placed at $-10{ }^{\circ} \mathrm{C}$ to euthanize the bumblebees. Locations where colonies had been removed were revisited during the next morning between 8:00 and 11:00 h to collect any bumblebees in the immediate vicinity $\left(0.25 \mathrm{~m}^{2}\right)$, which we assumed belonged to the colony at that location. Bumblebees were counted and body size was measured by thorax width $( \pm 0.5 \mathrm{~mm})$, a standard measurement of bumblebee size (Goulson et al. 
2002). Workers were distinguished from gynes by size, as there tends to be little overlap between worker and gyne size in pollen-storing bumblebees, such as B. impatiens (Goulson 2012). Males (drones, hereafter) could not be distinguished from workers and were therefore included in the worker count for all analyses (Goulson et al. 2002, Williams et al. 2012). This inclusion resulted in a loss of information regarding reproductive success. The impact of including drones in the worker count, however, was relatively low: Drones depart from the colony soon after they hatch to forage on flowers, search for mates (Cueva del Castillo and Fairbairn 2012), and, in contrast to gynes, permanently depart the hive (Goulson 2012). Thus, the number of drones in a colony is typically low in comparison to worker numbers. Colony size was defined as the number of workers and drones. Reproductive success of a colony was defined as the number of gynes.

\subsection{Floral surveys}

In May 2013, surveys were performed to estimate floral resources. In all fragments containing colonies $(N=32)$, floral resources were recorded within two $2 \mathrm{~m}$ x $35 \mathrm{~m}$ transects. Number of flowering plants with seed set (past food source), flowers (present food source), and flower buds (future food source) were counted. Only plant species on which bumblebee visits had been observed were recorded. Recorded plant species (with observed flowering times) were as follows: Baptisia perfoliata (L.; AprilMay), Erigeron strigosus (Muhl. ex Willd.; AprilMay), Gamochaeta purpurea (L.; April-May), Gelsemium sempervirens (L.; December-May), Mimosa microphylla (Dryand.; April-July), Opuntia humifusa (Raf.; May-July), Rhynchosia reniformis (DC.; May-August), Rubus spp. (April-July), Toxicodendron pubescens (Mill.; March-April), and Vaccinium stamineum (L.; May-June). One of the two transects was located close to the fragment edge, starting at a randomly selected corner and heading towards the fragment center. The other transect was located at the center of the fragment, starting at the center point and heading towards a randomly selected corner. The chosen transects did not overlap at their ends. Flowering plants recorded in both transects were summed to represent the amount of floral resources per fragment (hereafter local floral resources).

Similar floral surveys were performed within the forest surrounding the experimental fragments to evaluate the significance of the forest as a food source. Floral resources were recorded within four transects of $35 \mathrm{~m}$ length and $2 \mathrm{~m}$ width around all fragments containing colonies. Transects were located on lines which started at two randomly selected corners of the fragments, heading away from the fragment with an angle of $135^{\circ}$ from each of the two fragment sides joining at the corner. Flowering plants were recorded at distances between 0 and $35 \mathrm{~m}$ and between 70 and $105 \mathrm{~m}$ for each of the two lines.

\subsection{Surrounding open land}

To evaluate the impact of potential food sources outside of the experimental fragments on bumblebee colonies, the amount of open habitat within a $500 \mathrm{~m}$ radius around each hive was calculated using ArcMap (Esri, Redlands, CA, USA). Open habitat consisted mainly of roadways and power line clear cuts. The used radius was chosen because $500 \mathrm{~m}$ represents the distance, which lies within the foraging range of most bumblebee species (Goulson 2012) and at least one bumblebee species may cross up to $600 \mathrm{~m}$ of forest to reach floral resources (Kreyer et al. 2004).

\subsection{Statistical analyses}

Linear mixed-effects models were used to test hypotheses (i), (ii), and (iii). Colony mass gain, colony size, and reproductive success were used as dependent variables; connectivity (i), local floral resources (ii), and their interaction (iii) were used as independent variables. Amount of surrounding open habitat was added as a fourth dependent variable to test for possible effects of food sources outside of the experimental fragments. Blocks were treated as random effects. For mass gain, separate models were calculated for each weighing $(9,30$, and 51 days). AICc weights were calculated for each full model and the corresponding null model. Parameters for the best models were estimated using restricted maximum likelihood (REML). Additionally, the marginal $R^{2}$ values were calculated for each model. The significance of predictor variables was 
tested with ANOVA. Further, a linear model was used to investigate the relationship between mass gain, reproductive success, and colony size. Final mass gain was the dependent variable, and colony size and reproductive success were the independent variables. Analyses were carried out using the package nlme (Pinheiro et al. 2009) in R ver. 2.11.1 (R Core Development Team).

\section{RESULTS}

Most colonies flourished in our landscapes. Average colony mass increased $9 \mathrm{~g}$ (SD: $\pm 31 \mathrm{~g}), 194 \mathrm{~g}$ $( \pm 152 \mathrm{~g})$, and $538 \mathrm{~g}( \pm 299 \mathrm{~g})$ at 9,30 , and 51 days, respectively (Figure 2). In total, 23,391 bumblebee individuals, including 735 virgin queens, were counted. Workers and drones varied from 41 to 688 individuals per colony, and gynes varied from 0 to 94 individuals per colony. Both colony size $(t=11.1, \mathrm{df}=59, P<0.0001)$ and reproductive success $(t=2.6, \mathrm{df}=59, P=0.01)$ were reliable predictors of final colony mass. The heavier the colony, the more workers and reproductive individuals were produced.
AICc weights showed that the full model was superior to the null model for reproductive success and mass gain for the first and second weighing. In contrast, the null model was better supported than the full model for the third weighing and the colony size.

None of the measured colony fitness parameters significantly increased with increasing connectivity of the local fragment (hypothesis i; Table I, Figure 2). Similarly, the amount of open habitat in the surrounding landscape did not significantly affect colony size, colony mass, or reproductive success.

The amount of local floral resources was positively related to reproductive success $(F=12.7, P<0.01)$ and mass gain for the first $(F=4.6, P<0.05$; Figure 3$)$ and second weighing $(F=13.6$, $P<0.01$; hypothesis ii). Both the number of queens and colony mass gain increased significantly with increasing numbers of flowering plants within each colony's fragment (i.e., local floral resources). Neither colony size nor the last mass gain value were significantly influenced by local floral resources.

The slope of the relationship between local floral resources and reproductive success was significantly

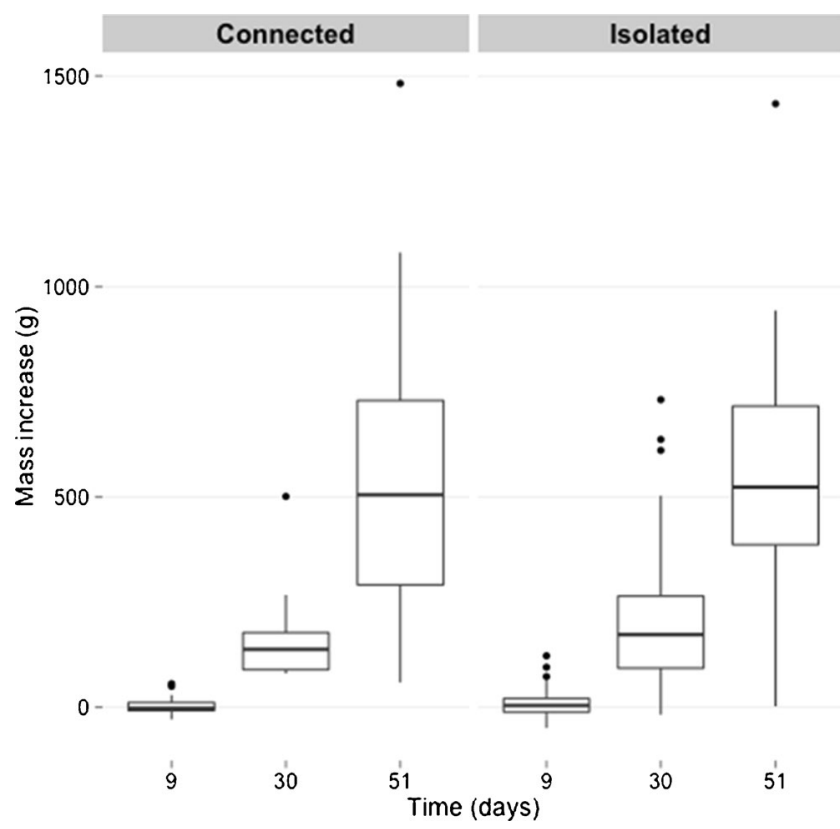

Figure 2. Boxplots of mass increases of 62 bumblebee colonies after 9, 30, and 51 days within connected (left) and isolated (right) fragments. Bold horizontal lines show the median, and the bottom and top horizontal lines of boxes show the 25th and 75th percentiles, respectively. Outliers greater than 1.5 times the interquartile range above the third quartile are depicted as points 


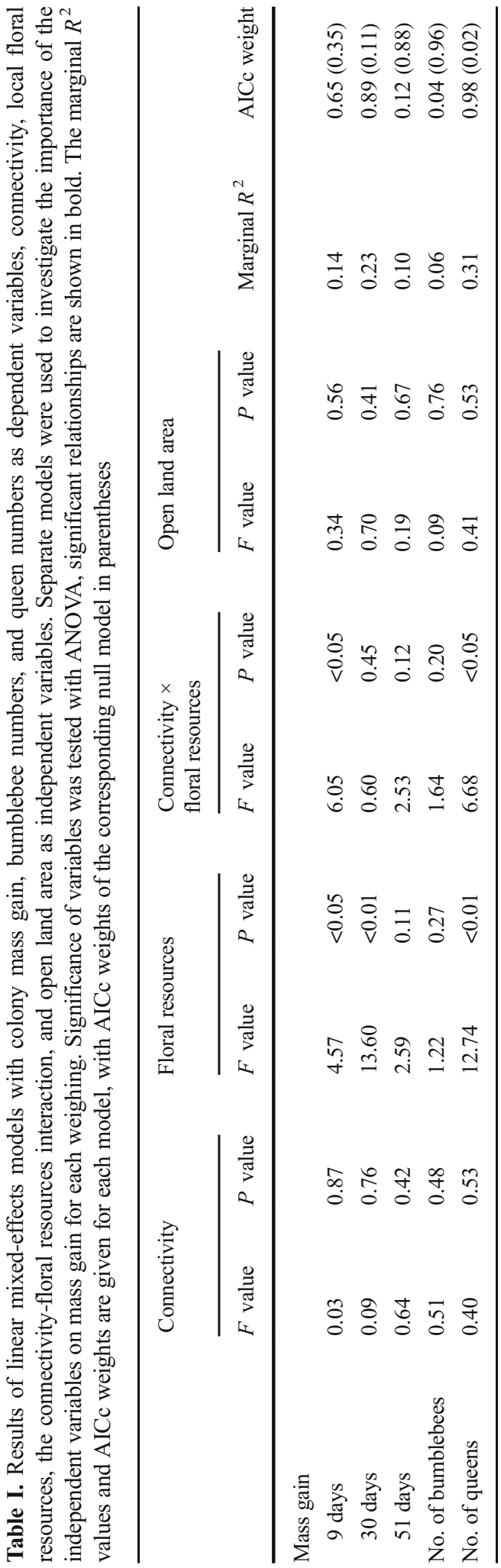

higher $(F=6.1, P<0.05)$ in isolated (slope $\beta_{2}=3.3$ ) compared to connected fragments (slope $\beta_{2}=-1.3$; hypothesis iii). Similarly, the slope of mass gain in relationship to local floral resources was significantly higher $(F=6.7, P<0.05)$ in isolated (slope $\beta_{2}=3.6$ ) compared to connected fragments (slope $\beta_{2}=-3.6$ ), but only for the first weighing. The effect of floral resources on colony size and the second and third mass gain measurements was not significantly different between isolated and connected fragments.

\section{DISCUSSION}

Landscape connectivity did not directly affect colony mass, colony size, or reproductive success of $B$. impatiens colonies (hypothesis i). The absence of a direct connectivity effect on bumblebee colonies in our study system has at least three possible explanations: bumblebee foraging was not affected by the forest because (a) the forest contained additional food sources or (b) because it did not represent a barrier to movement between fragments, or (c) bumblebees encountered sufficient floral resources within their colony's local fragment, making longdistance foraging trips unnecessary.

The first explanation (a) seems unlikely within the context of our experimental landscapes. In contrast to the rich herbaceous layer in the fragments, there was a sharp contrast with the surrounding pine forest, which was relatively depauperate (mean number of flowering plants $/ \mathrm{m}^{2} \pm \mathrm{SD}$ in fragments $=1.0 \pm 0.3$; in forest $=0.2 \pm 0.1$ ). The second explanation (b) is supported by prior research, which has shown that some bumblebees have the ability to cross forested areas in search of food (Kreyer et al. 2004). Within our experiment, however, the amount of open land areas around the experimental fragments had no positive effect on colony performance. The absence of a positive effect indicates that bumblebees either did not forage in these areas or that foraging in these areas was energetically inefficient.

The third explanation (c), which aligns conceptually with hypothesis (ii), was supported by our results. Local floral resources were a significant predictor of colony mass and reproductive success of $B$. impatiens, indicating that nearby resources 


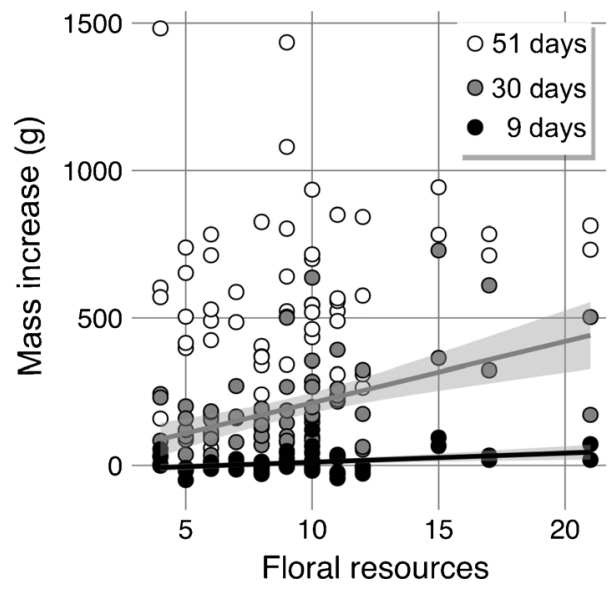

Figure 3. Scatterplot of local floral resources (number of flowering plants per transect) and mass increases ( $\mathrm{g}$ ) of 62 bumblebee colonies after 9, 30, and 51 days. Regression lines and their $95 \%$ confidence intervals are drawn for significant relationships, based on results from the linear mixed-effects model

within the fragments provided the main source of food for the colonies.

Studies investigating local vs. landscape floral composition on bee abundance have found that high-quality local habitat is important for bees in degraded landscapes (Williams \& Kremen 2007, Rundlof et al. 2008). The forest in our experimental landscapes can be considered degraded habitat for bumblebees, as only a few individual flowering plants were typically present along transects. Therefore, the forest may have increased the importance of local floral resources. Accordingly, the effect of local floral resources was higher in unconnected than in connected fragments (hypothesis iii). Both colony mass and reproductive success were more dependent on local floral resources in isolated than connected fragments, indicating a foraging limitation on local resources in isolated fragments.

Results of prior studies on preferred foraging distances of bumblebees in nondegraded landscapes have been ambiguous, with some suggesting mainly long foraging distances (Dramstad et al. 2003) while others suggesting most individuals forage in close proximity to their colony (e.g., Bowers 1985; Rotenberry 1990). In our study, local floral resources had a general positive effect on the mass of $B$. impatiens colonies. The positive effect of local resources, however, decreased below a significant level after 51 days, indicating that close resources might be especially important during the establishment phase of a colony, when only few workers are available for foraging and relatively limited (nearby) resources are sufficient to ensure colony growth. As the colony grows, intracolony competition for nearby resources might force individuals to increase their foraging range to ensure colony growth (Dramstad 1996), thereby decreasing the overall importance of close resources.

An alternative explanation for the temporal decrease in the importance of local floral resources involves our measurement of floral resources. The majority of plant species included in our measurements of floral resources had their peak flowering time in April and May, which is also when we weighed hives the first two times. Other flowers may have become more dominant later in the season, decreasing the predictive power of the measured floral resources for the last measured mass gain. Additionally, by the end of the experiment, some colonies had become limited by the space within the hive boxes, resulting in the establishment of wax structures on top of the hive boxes. These colonies might have had heavier colony masses if more space within the hive had been available. If so, the lack of sufficient space within the hives might have skewed the relationship between local floral resources and colony mass gain at the last weighing.

Both colony size and reproductive success were good predictors of colony mass. The correlations between these parameters were likely caused by our methodology, which included all bumblebees in calculation of colony mass. Despite the correlations of these colony parameters, however, only colony mass and reproductive success were significantly positively correlated with the number of flowering plants. The increase of colony structures, especially honey and pollen, may have triggered the increased reproductive success because developing queens require more food over a longer period than worker larvae (Goulson 2012). Accordingly, queen larvae can only be produced if sufficient food is available throughout the season (Westphal et al. 2009). 
A major cause of bumblebee decline is the loss of habitat to intensive farming. Subsidies for agri-environment schemes that promote biodiversity, such as sown flower strips, are currently implemented in many countries (Batary et al. 2015, Winfree 2010). We found that floral resources in a single large, seminatural fragment (1.375 ha) were sufficient to support at least two bumblebee colonies in landscapes comprised mostly of poor-quality habitat (i.e., very low flower density). Colonies produced $12.9 \pm 2.7$ (mean $\pm \mathrm{SE}$ ) new queens, which would have been available to reestablish colonies the following year, thereby providing pollination services into the future. Fragment sizes sufficient to support bumblebee colonies, however, might vary between regions, depending on the amount of floral resources of the focal habitat (Bennett et al. 2014), the resource availability in the surrounding habitats (Persson and Smith 2013), and competition with other pollinators (Goulson and Sparrow 2009).

Our study provides evidence that fitness of a central place forager was not directly affected by structural connectivity (presence of a habitat corridor), likely due to sufficient local resources. However, the importance of local resources for colony performance was higher in isolated fragments, and a positive effect of connectivity might emerge if local floral resources were insufficient or became depleted. These conditions could occur in habitat fragments with distinct spatiotemporal patterns of flower abundance within the season, as is often observed in agricultural landscapes (Williams et al. 2012).

Finally, connectivity may be important for bees and other pollinators with small foraging ranges, depending in part on proximity of nesting and foraging habitat (Walter-Hellwig and Frankl 2000). In contrast, bumblebees with large foraging ranges do not seem to be influenced by landscape context at any scale (Steffan-Dewenter et al. 2002). Besides foraging, connectivity might also become important to bumblebee persistence in fragmented landscapes by facilitating dispersal of queens. This potential role of corridors would be especially relevant for rare bumblebee species, which tend to have queens that disperse poorly (Lepais et al., 2010).

\section{ACKNOWLEDGEMENTS}

We thank the USDA Forest Service-Savannah River for creating and maintaining our experimental landscapes. We are particularly indebted to Chris Hobson, Paul Varnedoe, and the prescribed fire staff for assistance during this study, to John Blake, Ed Olson, and Kim Wright for support with site creation, daily logistics, and project management and to two anonymous reviewers, who helped improve the manuscript. This project would not have been possible without the invaluable dedication of many technicians, especially Jennifer Chandler and Mike Epperly. For financial support, we thank the Department of Agriculture, Forest Service, Savannah River (a National Environmental Research Park), under Interagency Agreement DEAI09-00SR22188 with the Department of Energy, Aiken, South Carolina, and the National Science Foundation (DEB- 1050361).

Evaluation de l'importance relative des ressources locales et de la connectivité du paysage sur les colonies de Bombus impatiens (Hymenoptera, Apidae)

Schémas agri-environnementaux / distance des sources d'approvisionnement / facteur paysage / habitat fragmenté / ressources florales

Bewertung der relativen Bedeutung von lokalen Ressourcen und Landschaftskonnektivität auf Bombus impatiens (Hymenoptera, Apidae) Kolonien .

Agrarumweltmaßnahmen / Reichweite der Nahrungsuche / Habitatfragmentierung / Blütenressourcen

\section{REFERENCES}

Bailey, D., Schmidt-Entling M.H., Eberhart P., Herrmann J.D., Hofer G., Kormann U., Herzog F. (2010) Differentiating effects of habitat amount and isolation on biodiversity. J. Appl. Ecol. 47, 1003-1013

Batary, P., Dick, L.V., Kleijn D., Sutherland, W.J. (2015) The role of agri-environment schemes in conservation and environmental management. Conserv. Biol. 29, 1006-1016

Bennett J.A., Gensler G.C., Cahill Jr. J.F. (2014) Smallscale bee patch use is affected equally by flower availability and local habitat configuration. Basic Appl. Ecol. 15, 260-268

Bodin, Ö., Tengö, M., Norman, A., Lundberg, J., Elmqvist, T. (2006) The value of small size: loss of forest patches 
and ecological thresholds in southern Madagascar. Ecol appl 16, 440-451.

Bowers, M. A. (1985) Bumblebee colonization, extinction and reproduction in subalpine meadows in northeastern Utah. Ecology 66, 914-927

Committee on the Status of Pollinators in North America (2007) Status of pollinators in North America. The National Academic Press, Washington, DC.

Cranmer, L., McCollin, D., Ollerton, J. (2012) Landscape structure influences pollinator movements and directly affects plant reproductive success. Oikos 121, 562-568

Cueva del Castillo R., Fairbairn D.J. (2012) Macro evolutionary patterns on bumblebee body size: detecting the interplay between natural and sexual selection. Ecol. Evol. 2, 46-57

Cunningham, S.A. (2000) Depressed pollination in habitat fragments causes low fruit set. Proc. R. Soc. B Biol. 267, 1149-1152

Daily, G.C. (1997) Nature's services: social dependence on natural ecosystems. Island Press, Washington DC.

Doerr, V.A.J., Barrett, T., Doerr E.D. (2011). Connectivity, dispersal behavior and conservation under climate change: a response to Hodgson et al. J. Appl. Ecol. 48, 143-147

Dramstad W.E. (1996) Do bumblebee (Hymenoptera: Apidae) really forage close to their nests? J. Insect Behav. 2, 163-182

Dramstad W.E., Fry G.L.A., Schaffer M.J., (2003) Bumblebee foraging - is closer really better? Agric. Ecosyst. Environ. 95 , 349-357

Fahrig, L. (2013) Rethinking patch size and isolation effects: the habitat amount hypothesis. J. Biogeogr. 40, 1649-1663.

Goulson, D. (2012) Bumblebees - behavior, ecology, and conservation. Oxford University Press, Oxford

Goulson, D., Peat, J., Stout, J. C., Tucker, J., Darvill, B., Derwent, L. C., Hughes, W. O. (2002). Can alloethism in workers of the bumblebee, Bombus terrestris, be explained in terms of foraging efficiency?. Anim Behav 64 (1), 123-130

Goulson D, Sparrow K. (2009) Evidence for competition between honeybees and bumblebees; effects on bumblebee worker size. J. Insect Conserv. 13, 177-181

Haddad, N.M. (1999) Corridor and distance effects on interpatch movements: a landscape experiment with butterflies. Ecol. Appl. 9, 612-622

Haddad, N.M., Tewksbury J.J. (2005) Low-quality habitat corridors as movement conduits for two butterfly species. Ecol. Appl. 15 : 250-257

Haddad, N. M., Brudvig, L.A, Clobert, J., Davies, K.F., Gonzalez, A. et al. (2015) Habitat fragmentation and its lasting impact on Earth's ecosystems. Sci. Adv. 1, e1500052

Hadley, A.S., Betts, M.G. (2012) The effects of landscape fragmentation on pollination dynamics: absence of evidence not evidence of absence. Biol. Rev. 87, 526-544
Heard, M.S., Carvell, C., Carreck, N.L., Rothery, P., Osborne, J.L., Bourke, A.F.G. (2007) Landscape context not patch size determines bumble-bee density on flower mixtures sown for agri-environment schemes. Biol. Lett. 3, 638-641

Herrmann, J. D., Carlo, T. A., Brudvig, L. A., Damschen, E. I., Haddad, N. M., Levey, D. J., Orrock, J. L., Tewksbury, J. J. (2016) Connectivity from a different perspective: comparing seed dispersal kernels in connected vs. unfragmented landscapes. Ecology 97, 1274-1282

Hilty, J.A., Lidicker Jr, W.Z., Merenlender, A., Dobson, A.P. (2006) Corridor ecology: The science and practice of linking landscapes for biodiversity conservation. Island Press, Washington, D.C., USA.

Hodgson, J.A., Thomas, C.D., Wintle, B.A., Moilanen, A. (2009) Climate change, connectivity and conservation making: back to basics. J. Appl. Ecol. 46, 964-969

Hodgson, J.A., Moilanen, A., Wintle, B.A., Thomas, C.D. (2011) Habitat area, quality and connectivity: striking the balance for efficient conservation. J. Appl. Ecol. 48, 148-152

Hopfenmüller, S., Steffan-Dewenter, I., Holzschuh, A. (2014) Trait-specific responses of wild bee communities to landscape composition, configuration and local factors. PLOS ONE, doi: 10.1371/journal. pone.01034439

Kremen, C., Williams, N.M., Thorp, R.W. (2002) Crop pollination from native bees at risk from agricultural intensification. Proc. Natl. Acad. Sci. US 99, 1681216816

Kreyer, D., Oed, A., Walther-Hellwig, K., Frankl, R. (2004) Are forests potential barriers for foraging bumblebees? Landscape scale experiments with Bombus terrestris agg. And Bombus pascuourm (Hymenoptera, Apidae). Biol. Conserv. 116, 111118

Kuefler, D., Hudgens, B., Haddad, N. M., Morris, W. F., Thurgate, N. (2010) The conflicting role of matrix habitats as conduits and barriers for dispersal. Ecology 91 : 944-950

Lepais, O., Darvill, B., O'Connor, S., Osborne, J.L., Sanderson, R.A., Cussans, J., Goffe, L., Goulson, D. (2010) Estimation of bumblebee queen dispersal distances using sibship reconstruction method. Mol. Ecol. 19, 819-831

McGarigal, K., Cushman, S.A., (2002) Comparative evaluation of experimental approaches to the study of habitat fragmentation effects. Ecol. Appl. 12, 335-345

Persson A.S., Smith H.K. (2013) Seasonal persistence of bumblebee populations is affected by landscape context. Agric. Ecosyst. Environ. 165, 201-209

Pinheiro, J., Douglas, B., DebRoy, S., Sarkar, D., R Core team (2008) NLME: linear and nonlinear mixed effects models. R package version 3, pp s1-89

Potts, S.G., Biesmeijer, J.C., Kremen, C., Neumann, P., Schweiger, O., Kunin, W.E. (2010) Global pollinator declines: trends, impacts and drivers. Trends Ecol. Evol. 25, 345-353 
Rotenberry, J. T. (1990) Variable floral phenology: temporal resource heterogeneity and its implications for flower visitors. Holarctic Ecol. 13, 1-10

Rundlof, M., Nilsson, H., Smith, H.G. (2008) Interacting effects of farming practice and landscape context on bumblebees. Biol. Conserv. 141, 417-426

Schüepp, C., Herrmann, J.D., Herzog, F., Schmidt-Entling, M.H. (2011) Differential effects of habitat isolation and landscape composition on wasps, bees and their enemies. Oecologia 165, 713-721

Steffan-Dewenter, I., Tscharntke, T. (1999) Effects of isolation on pollinator communities and seed set. Oecologia 121, 432-440

Steffan-Dewenter I., Münzenberg U., Bürger C., Thies C., Tscharntke T. (2002) Scale-dependent effects of landscape context on three pollinator guilds. Ecology 83, 1421-143

Steffan-Dewenter, I., Potts, S. G., Packer, L. (2005) Pollinator diversity and crop pollination services are at risk. Trends Ecol Evol 20, 651-652.

Tewksbury, J.J., Levey, D.J., Haddad, N.M., Sargent, S., Orrock, J.L., Weldon, A., Danielson, B.J., Bringkerhoff, J., Damschen, E.I., Townsend, P. (2002) Corridors affect plants, animals, and their interactions in fragmented landscapes. Proc. Natl. Acad. Sci. USA 99, 12923-12926

Tischendorf, L., Fahrig, L. (2000) On the usage and measurement of landscape connectivity. Oikos 90, 7-19
Townsend, P.A., Levey, D.J. (2005) An experimental test of whether habitat corridors affect pollen transfer. Ecology 86, 466-475

Walter-Hellwig K., Frankl R. (2000) Foraging habitats and foraging distances of bumblebees, Bombus spp. (Hym., Apidae), in an agricultural landscape. J. Appl. Entomol. 124, 299-306

Westphal, C., Steffan-Dewenter, I., Tscharntke, T. (2006) Bumblebees experience landscapes at different spatial scales: possible implications for coexistence. Oecologia 149, 289-300

Westphal, C., Steffan-Dewenter, I., Tscharntke, T. (2009) Mass flowering oilseed rape improves early colony growth but not sexual reproduction of bumblebees. J. Appl. Ecol. 1, 187-193

Williams, N.M., Kremen, C. (2007) Resource distributions among habitats determine solitary bee offspring production in a mosaic landscape. Ecol. Appl. 17, 910921

Williams, N.M., Regetz, J., Kremen, C. (2012) Landscapescale resources promote colony growth but not reproductive performance of bumble bees. Ecology 93 , 1049-1058

Winfree, R. (2010) The conservation and restoration of wild bees, in: Ostfield, R.S., and Schlesinger, W.H. (Eds.), Year in ecology and conservation biology 2010. Ann. NY Acad. Sci. 1195, 169-197 